\title{
Individualised treatment improves depression in people with depression and diabetes
}

Katon WJ, Von Korff M, Lin EHB, et al. The Pathways study: a randomized trial of collaborative care in patients with diabetes and depression. Arch Gen Psychiatry 2004;61:1042-9.

Does an individualised treatment programme improve depression in people with depression and diabetes mellitus?

\section{METHODS}

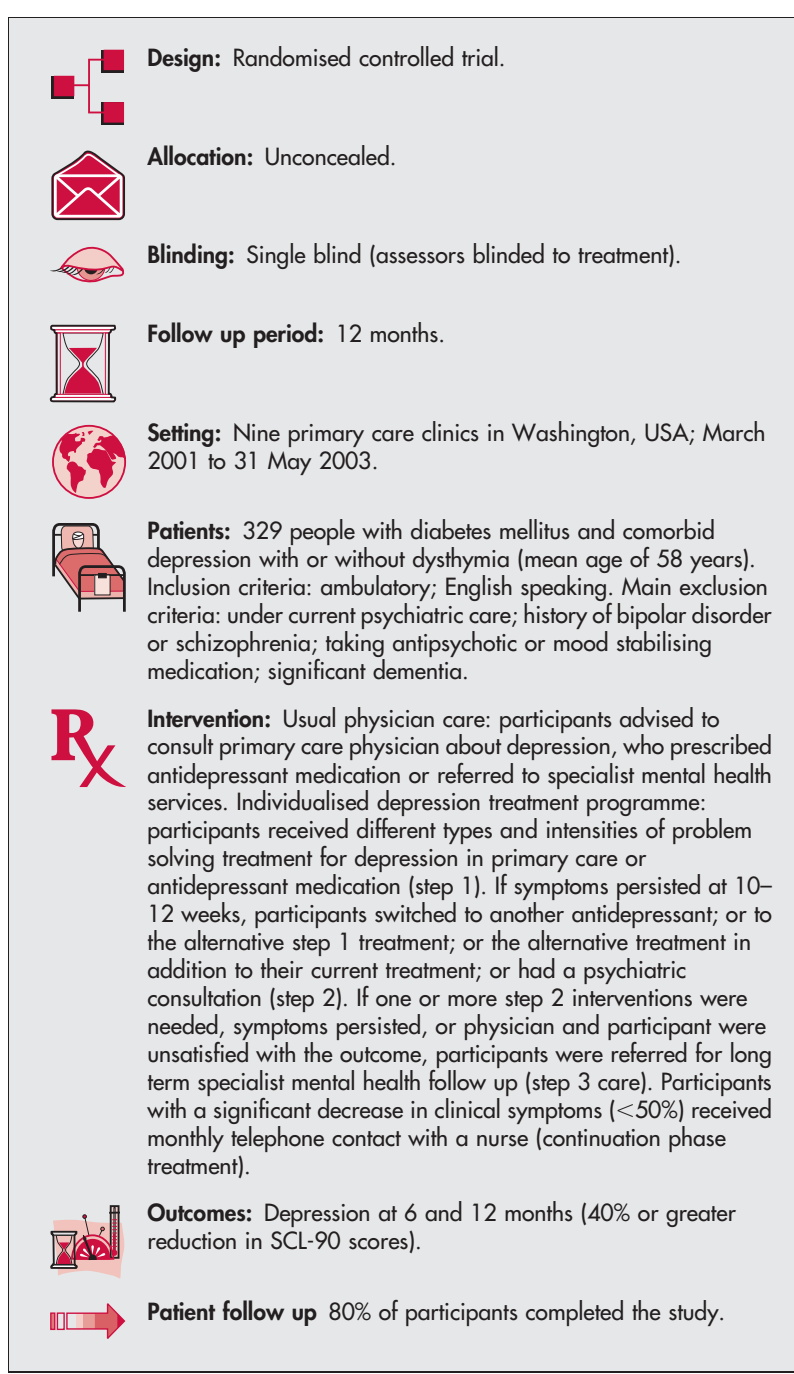

\section{MAIN RESULTS}

The individualised treatment programme significantly improved depression compared with usual care at 12 months (proportion of participants with a $40 \%$ or more decrease in SCL-90 depression score: $79 / 288(54.1 \%)$ with individualised treatment $v 54 / 288$ (38.0\%) with usual care; OR $1.89,95 \%$ CI 1.18 to 3.02 ).

For correspondence: Wayne J Katon, MD, Health Services Research and Psychiatric Epidemiology, Department of Psychiatry and Behavioral Sciences, Campus Box 356560, University of Washington School of Medicine, 1959 NE Pacific, Seattle,WA98195-6560; wkaton@u.washington.edu

Sources of funding: Grants MH4-1739 and MHO1643 from the National Institute of Mental Health Services Division, Bethesda, MD, USA.

\section{CONCLUSIONS AND NOTES}

A programme of individualised depression treatment is more effective than usual care for treating depression in people with depression and diabetes.

Expressing the results as odds ratios when the event rates are high can be misleading if interpreted as a relative risk. In this case, it overstates the relative risk, which we calculate to be 1.4 .

Commentary

aton et al's Pathways study is a well designed "practical clinical trial" ${ }^{1}{ }^{2}$ It used established principles congruent with both the Chronic Care Model ${ }^{3}$ and the US Preventive Services Task Force guidelines for behavioural counselling. ${ }^{4}$ People representative of those commonly seen in primary care settings were provided with choices for depression treatment, with follow up support and stepped care for nonresponders. This practical, flexible, and patient centred approach to depression care resulted in a clinically significant improvement in depression-but not in diabetes, which was not treated directly. Thus, the behavioural principle of specificity appears to hold: "If one wants generalization, one needs to program it, not simply hope for it" ${ }^{\prime \prime} .5$

Those receiving the intervention fared significantly better than those receiving usual care (NNT $=10$ for $\geqslant 50 \%$ improvement in depression symptoms; NNT = 3.5-4 for global improvement). No formal economic analyses were presented, but the programme appears feasible and efficient; follow up calls could be challenging since nurse calls are often not reimbursable. Data on depression remission, relapse (although 12 months may be insufficient time to see significant differences in relapse), diabetes self-management behaviours, and overall quality of life were not reported. Intervention may be needed for each condition in comorbid patients (at least for diabetes and depression)-treating depression does not generalise to diabetes (and vice versa). ${ }^{6}$ Ideally, biopsychosocial interventions using concepts applicable to both depression and diabetes (self-efficacy, exercise, medication adherence) would be delivered by a single care manager (rather than one for diabetes and another for depression). Many of the same principles apply to diabetes as well as depression and other chronic illnesses. ${ }^{78}$ Thus, the tools and resources with which clinical teams need to be familiar seem to be generic-but in order to be effective, they may need to be targeted to each specific condition or target of focus.

Russell E Glasgow, PhD, and David W Price, MD Kaiser Permanente Colorado, Denver, CO, USA

1 Tunis SR, Stryer DB, Clancey CM. Practical clinical trials. Increasing the value of clinical research for decision making in clinical and health policy. JAMA 2003;290:1624-32.

2 Glasgow RE, Magid DJ, Beck A, et al. Practical clinical trials for translating research to practice: design and measurement recommendations. Med Care (in press).

3 Wagner EH, Austin B, Von Korff M. Improving outcomes in chronic illness. Manag Care Q 1996;4:12-25.

4 Whitlock EP, Orleans CT, Pender N, et al. Evaluating primary care behavioral counseling interventions: An evidence-based approach. Am J Prev Med 2002;22:267-84.

5 Parsonson BS, Baer AM, Baer DM. The application of generalized correct social contingencies: An evaluation of a training program. J Appl Behav Anal 1974;7:427-37.

6 Grant RW, Hamrick HE, Sullivan CM, et al. Impact of population management with direct physician feedback on care of patients with type 2 diabetes. Diabetes Care 2003;26:2275-80.

7 Lorig KR, Holman HR. Self-management education: history, definition, outcomes, and mechanisms. Ann Behav Med 2003:26:1-7.

8 Glasgow RE, Goldstein MG, Ockene J, et al. Translating what we have learned into practice: Principles and hypotheses for addressing multiple behaviors in primary care. Am J Prev Med 2004;27:88-101. 